\title{
Jean-Marc Ticchi, Histoire de la province française de l'Ordre de Saint Camille de Lellis
}

Paris, l'Harmattan, 2014, $258 \mathrm{p}$.

Avant-propos d'Andrea Ciampani.

\section{Claude Langlois}

\section{(2) OpenEdition}

Journals

Édition électronique

URL : http://journals.openedition.org/assr/27473

DOI : $10.4000 /$ assr.27473

ISSN : $1777-5825$

Éditeur

Éditions de l'EHESS

Édition imprimée

Date de publication : 1 octobre 2015

Pagination : 381

ISBN : 978-2-7132-2515-4

ISSN : 0335-5985

Référence électronique

Claude Langlois, « Jean-Marc Ticchi, Histoire de la province française de l'Ordre de Saint Camille de Lellis ", Archives de sciences sociales des religions [En ligne], 172 | octobre-décembre, mis en ligne le 21 juin 2016, consulté le 23 septembre 2020. URL : http://journals.openedition.org/assr/27473 ; DOI : https://doi.org/10.4000/assr.27473

Ce document a été généré automatiquement le 23 septembre 2020.

() Archives de sciences sociales des religions 


\section{Jean-Marc Ticchi, Histoire de la province française de l'Ordre de Saint Camille de Lellis}

Paris, l'Harmattan, 2014, 258 p.

Avant-propos d'Andrea Ciampani.

Claude Langlois

\section{RÉFÉRENCE}

Jean-Marc Ticchi, Histoire de la province française de l'Ordre de Saint Camille de Lellis, Paris, l'Harmattan, 2014, 258 p.

Avant-propos d'Andrea Ciampani. 
1 Cet ouvrage s'inscrit dans une recherche collective sur l'histoire des diverses provinces de l'ordre de Saint Camille de Lellis dont le maître d'œuvre est le professeur Ciampani. Le présent volume constitue la version française de la Storia dell'Ordine di San camillo. La Provincia Francese. Quatre autres volumes de cette même collection sont consacrés aux trois provinces italiennes et la province germanique. Cette précision peut n'être pas inutile pour comprendre une rédaction en quatre chapitres chronologiques (implantation, développement, crise, renouveau) suivi d'un dernier plus synthétique. Cette histoire, d'une érudition impeccable, est puisée à des sources de première main, elles-mêmes analysées avec finesse. Ticchi restitue avec bonheur la modeste montée en puissance, en France, d'une

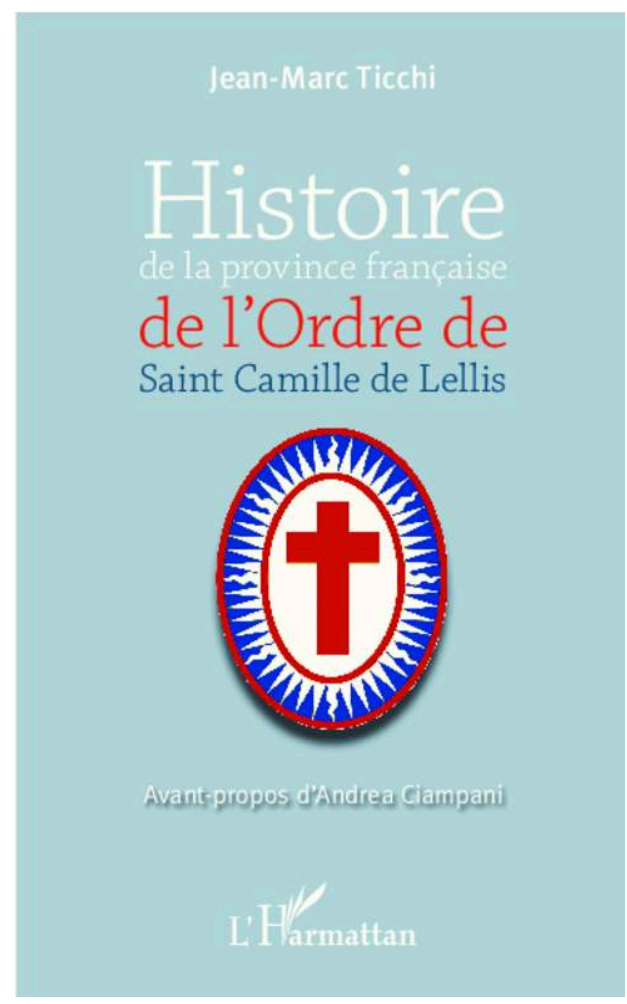
congrégation ancienne, fondée par Camille de Lellis (1550-1614) : cet ordre, comme l'indique son nom officiel, les serviteurs des malades, oblige ses membres, par un quatrième vœu, à se mettre au service de ces derniers, même au péril de leur vie. Les Camilliens, dispersés à la fin du XVIII ${ }^{\mathrm{e}}$ siècle, ont repris vie en Italie au XIX ${ }^{\mathrm{e}}$ siècle et ont été introduits en France en 1869 à partir de la dynamique province de Vénétie qui, face à la politique italienne hostile aux religieux, cherchait une terre possible d'accueil. Vue de France, cette arrivée discrète des disciples de Camille de Lellis s'inscrit dans le droit fil d'une présence nouvelle, depuis le milieu du XIX ${ }^{\mathrm{e}}$ siècle, de congrégations italiennes dynamiques, Rédemporistes (Alphonse de Liguori), Paulistes (Paul de la Croix), voire membres de l'Oratoire italien (Philippe de Néri).

2 Les religieux de la province française n'atteignent pas le millier : au total, en 65 ans, seulement 850 jeunes hommes de plusieurs pays se sont présentés comme postulants sans nécessairement persévérer. De ce fait, la progression des effectifs a été très lente : 30 religieux en 1877, quand l'ordre crée un embryon de province française ; 82 en 1889 ; 100 seulement en 1920 ; un maximum de 200 en 1935. Les débuts laborieux témoignent au moins de la ténacité des religieux italiens fondateurs des premières maisons. L'implantation de l'ordre se heurte en effet à de multiples obstacles : la date tardive de son arrivée à la veille de la crise de $1870-1871$, la politique républicaine hostile aux congrégations qui entraîne la fermeture des maisons en 1880 puis plus durablement en 1901-1904, la volatilité du premier recrutement français, le coût élevé des fondations pour le soin des malades et enfin la féminisation massive des activités hospitalières à l'exception des Frères de Sain-Jean-de-Dieu. Il faut ajouter un point essentiel qui aurait mérité approfondissement, la difficulté des Camilliens à choisir des «cibles » et à s'y tenir: en effet la congrégation hésite entre la satisfaction d'une forte demande épiscopale (hospices pour prêtres âgés), la nécessité de trouver des activités 
rémunératrices (le soin et l'accompagnement de malades aisés), la recherche de pathologies nouvelles nécessitant un encadrement spécifique (alcooliques, puis tuberculeux) ou encore l'insertion, réussie, dans l'important réseau hospitalier de l'Institut catholique de Lille. Les refuges belge et irlandais ont permis à l'ordre de survivre à la suppression des maisons françaises au début du $\mathrm{xx}^{\mathrm{e}}$ siècle. Mais toutefois les implantations antérieures avaient porté des fruits et permis une véritable nationalisation de la province française au début $d u \mathrm{xx}^{\mathrm{e}}$ siècle et une réussite modeste, mais réelle, durant l'entre-deux-guerres. Des faits nouveaux expliquent aussi ce renversement de conjoncture : l'efficacité du premier supérieur français, le Père Deloux (1907-1923), le poids des «Alsaciens » (la moitié des effectifs au lendemain de la guerre) qui ont sans doute - mais on aurait aimé le savoir précisément - importé le modèle hospitalier allemand, le déclin en France de l'hostilité envers les religieux et plus encore de nouveaux besoins en zones périurbaines comme en témoigne l'insolite soutien au projet d'hôpital à Bry-sur-Marne apporté par le socialiste Allemane. On regrettera d'autant plus que le film s'arrête en 1935, même si l'on nous assure que l'ordre, qui compte présentement cinquante-cinq maisons de par le monde, en dispose encore de cinq en France. 